\title{
MeIPeAS: An Intelligent Virtual Tutor for Mexican Elementary Schoolchildren
}

\author{
Hector Rafael Orozco Aguirre, Gonzalo Ivan Riego Caravantes \\ University Center UAEM Valley of Mexico, \\ Autonomous University of Mexico State, Mexico \\ hrorozcoa@uaemex.mx, vannlink@hotmail.com
}

\begin{abstract}
It is known that virtual tutors have a wide range of functionalities, which have been little exploited and applied in the educational field at the primary level. However, these functionalities allow to offer mechanisms of interaction with students through an interactive dialogue by using text to speech, and even more sophisticated, the recognition and understanding of natural language or speech. In this paper, a personalized virtual tutor for the primary education scenario in Mexico is presented. This virtual tutor is called Mexican Intelligent Pedagogical Agent for Schoolchildren (MeIPeAS) and was created to be used as a pedagogical support mechanism offering a unique attraction for current and future generations of schoolchildren in Mexico. The virtual tutor has been validated in practice in public primary schools of the municipalities of the State of Mexico in Mexico. This validation is to analyze the impact of the user experience from the obtained results having relevant information about the reinforcement of topics taught within the classroom.
\end{abstract}

Keywords: education, intelligent agent, pedagogical agent, virtual dialogue, virtual tutor.

\section{Introduction}

Interactive agents used for pedagogical purposes have demonstrated to induce a higher motivation to learn on students. These agents known as pedagogical agents would enhance learning when attracting attention through a dynamic interactive and conversational mechanism with students by a bidirectional dialog. Pedagogical agents look like anthropomorphic virtual characters used primarily for educational or training purposes. The design of pedagogical agents has changed over time depending on the desired objectives through their use. This field of research has emerged over the past three decades to provide support and achieve an adequate teaching-learning process according to the student and teacher needs. Apart of being able to communicate in a verbal way, it is desirable that created pedagogical agents are full bodied, and can show emotions or facial expressions even body motions in order to be able to communicate in a non-verbal manner with students. There exist different ways to animate and represent pedagogical agents, some of the most common are: using a cartoon-style character, playing real videos or employing $2 \mathrm{D}$ or $3 \mathrm{D}$ models.

Pedagogical agents, which are able to show affective reactions, have expressive behaviors, exhibit a personality, speak and listen to the user. These can offer a further 
dimension to the experience of human-computer interaction applications for learning purposes. Their construction makes possible to extend the experience within the learning environment by enhancing communicative setting, delivering a capability where the spoken output can be enhanced by expressive talking agents that can understand student speech and are capable to speech to them. The point of departure for the approach described in this paper is that this agent technology can be used in the development of an effective pedagogical agent in the form of an intelligent virtual tutor for supporting and assisting the teaching-learning process within the first three grades of primary education in Mexico.

Given the above, in this paper a virtual tutor prototype called Mexican Intelligent Pedagogical Agent for Schoolchildren (MeIPeAS) is presented, as a new tool based on human-computer interaction techniques through the approaches of serious games [1] [2] and educational software [3] [4]. That is, so that students into the first three grades of primary education in Mexico can interact with it, while seeking to achieve understanding and master the acquired knowledge in each theme of each block included in all subjects that must be studied.

The interactive virtual tutor here presented is intended to support the teachinglearning process within the classroom, not as a substitute for a real tutor or teacher, but as a pedagogical support element even at home. This virtual tutor represents a new working tool that can be used in teaching, and helps in the increase and remarkable improvement of the educational quality from primary education levels, being one of the first pedagogical agents developed in Mexico. This agent inhabits a serious game acting as an individualized teaching-learning platform and intelligent tutoring system. With the use of the virtual tutor (see fig. 1), it will be verified that it is feasible to provide a supporting tool for the improvement of educational didactics, as well as a reinforcement of the subjects taught in the first three grades of primary education in Mexico, seeking to demonstrate that means of reinforcement exercises for the subjects included in the current curriculum, a simple, creative, dynamic, intuitive and fun interaction mechanism is achieved, which assists and supports the teaching-learning process by impacting the user experience in a positive manner.

\section{Pedagogical Agents and their Applications}

Animated agents are graphical representations of characters used in computer interfaces where a human-computer interaction in a more personalized way and natural style is preferred to be present among users and agents. These virtual characters have been created for a wide variety of computer applications such as virtual presenters, training agents, and pedagogical agents. In pedagogical applications, users tend to prefer a learning system which employs an animated agent to a similar one without an agent. Animated pedagogical agents are often designed as human-like characters that facilitate the learning process and support students in solving activities in learning platforms. These kind of agents is also a useful tool as an aid for teachers in schools during learning activities. The use of animated agents in pedagogical applications has been effective in intelligent tutoring systems in which students can improve the learning experience by engaging dialogue or conversation with agents, that is, a learning environment can be enhanced with the addition of animated agents. When a pedagogical agent is facially 
animated within a learning platform students experience a more natural learning process because the agent positively affects student's perception of their own learning experience by its presence.

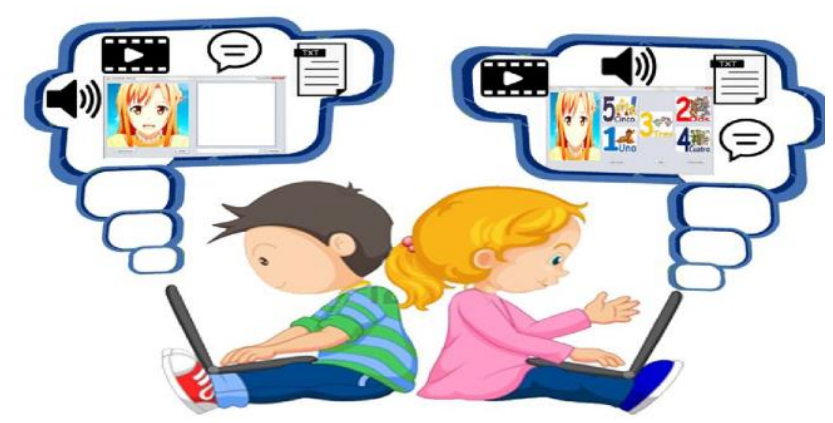

Fig. 1. Individual use of the presented pedagogical virtual tutor within a teaching-learning environment for Mexican schoolchildren.

In [5] cited by [6], authors detail types of interaction that agents can display, which benefit the learning context, and also described the following benefits that animated pedagogical agents can bring to human-computer interaction applications:

- Pedagogical agents are able to provide to students how to perform a particular task. They can virtually show how to complete a task into a virtual learning environment.

- Pedagogical agents can act as navigational guides to students in complex learning environments.

- Pedagogical agents can steer a student's attention to something in the virtual world by way of gaze behaviors and deictic gestures.

- Pedagogical agents can provide non-verbal feedback to a student's input or actions, as well as verbal feedback.

- Pedagogical agents are able to express conversational signals which people are accustomed to in human-human interaction, for turn taking, expressing personal opinions or acknowledging the user's utterance.

- Pedagogical agents can convey emotion to the user which in turn may elicit emotion from the user and serve to increase learning motivation.

- Pedagogical agents can serve the role of a virtual teammate, where working in a team is an element of the task design. Here, the agent can either act as an instructor, helping the student to accomplish a task, or substitute as a missing team member, allowing the student to practice working in a team.

According to [7], an agent can exist within the learning environment, but it is also possible for an agent to exist in a separate window. In addition, it is preferred that the behavior be generated ideally online and in a dynamic way instead of being created offline or manually. A dynamic behavior is better and corresponds to the changes into the learning environment.

Previous efforts on pedagogical agents include empirical researches about their uses, effectiveness, or limitations. The most representative examples of successful on agent- 
based learning applications are summarized in [8]. Some of these pedagogical applications are the following:

- Hernan the Bug: the first agent developed to inhabit virtual environments to help middle school students to understand botanical anatomy and physiology.

- Soar Training Expert for Virtual Environments (STEVE): this was designed to interact with students in networked virtual environments and applied to naval training tasks.

- Cosmo: a life-like animated agent with deictic believability that occupies the Internet Adviser for helping learners on Internet packet routing.

- PPP Persona: it was created to guide the learner through web-based material using presentation acts to draw attention to elements of the web pages, and provide commentary via synthesized speech.

- JACK: a virtual human that exhibits a variety of different deictic gestures as a virtual presenter who can point at individual elements on his visual aid and integrates these gestures into his presentation, moving over to the target object before his speech reaches the need for the deictic gesture.

- ADELE: an agent designed to operate over the web able to extend the pedagogical capabilities of STEVE agent in a wider range of educational problems.

- VINCENT: a tutor friend for on-the-job training to assist the student, promote his confidence and motivate the student to learn.

Recent efforts on pedagogical agents show how agents and applications evolved in order to provide better learning platforms and solutions with less restrictions, where students expect agents to be believable as virtual mentors, be entertaining, easy to communicate, helpful, and diversified. In [8], there are also explained some of the most relevant agents, which are the next ones:

- Automated Lab Instructor (ALI): this agent provides flexible guidance to students interacting with virtual labs and had been applied to chemistry and biology simulations and also its application to virtual factory teaching system after that provided further evidence of its generality.

- MASCARET: a pedagogical multi-agent system for training proposed to organize the interactions between agents and to provide them reactive, cognitive and social abilities to simulate the physical and social environment.

- SKIP: a puppet agent used to improve science learning through the use of digital puppets in peer teaching and collaborative learning settings.

- Mediating Agent of MACES: an animated agent that has the role of providing emotional support and promoting in student a positive mood.

- MENTOR: a virtual teacher who monitors student activities and collaborates to other guide agents of environment. It allows users to travel to virtual places to perform educational activities, talk with other users and mentors, and build virtual personae.

Kim and Baylor [9] review what students want from a pedagogical agent it is a good teaching ability to be knowledgeable and the ability to give motivation being friendly 
and kind when using various instructional strategies in an interactive learning environment. Students significantly learn better and have greater motivation when working with two agents (split persona effect) than with one mentor agent. Mixed design factors of pedagogical agent research significantly improve learning performance and student behavior. A good example is described in [10], where a virtual tutor called Ms. Readwrite gives hints and explanations to help children to figure out answers while learning about phonological awareness, reading, spelling, and comprehension. This virtual tutor helps children learn to recognize words, to read fluently, and to understand what they read, providing engaging practice with individualized support and focused hints. My Science Tutor (MyST) is described in [11], representing an intelligent tutoring system designed to improve science learning by students in 3rd, 4th, and 5th grades through conversational dialogs with a virtual science tutor. Individual students engage in spoken dialogs with the virtual tutor Marni during 15 to 20 minute sessions following classroom science investigations to discuss and extend concepts embedded in the investigations. The spoken dialogs in MyST are designed to scaffold learning by presenting open-ended questions accompanied by illustrations or animations related to the classroom investigations and the science concepts being learned.

As shown in [12], some of the motivation theories are used as part of the pedagogical agent design. The most frequently used in pedagogical agent research is the social agency theory as a theoretical framework, assuming that sounds and images in pedagogical agents build social cues and trigger social responses improving deeply learning in student activities. As a final argument, it is argued that a pedagogical agent should tend to be a teachable agent able to learn while teaching. Blair et al. [13] defined a teachable agent as a one that works by letting students teach them and then assessing their knowledge by providing a series of questions to solve problems. In [14], it is mentioned that learning-by-teaching pedagogy has been identified as one of the more effective approaches to learning, because in a face-to-face learning-by-teaching situation, the role of the learners is to teach their peers or instructors. In virtual environments, learners take an active role by teaching a computer agent, which is referred to as teachable agent. In this way, a virtual learning-by-teaching environment is presented. A communication method was adopted in this system. The method facilitates the interaction between the learner and the computer agent, specifically for K-12 students' mathematics learning.

According to [15], due to pedagogical agents are becoming more common and complex, it is important to develop a better understanding of how best to combine interactive agents with teachers and students, to complement and make the learning process most effective and positive. Pedagogical agents should not be seen as taking the place of teachers but as a supporting tool in the learning process within the classroom [16].

\section{Mexican Education Scene}

In Mexico, a good quality education [17] can be sustained if it contains the following attributes: relevance, pertinence, internal efficacy, external efficacy, quality, sufficiency, good educational results, and equity. However, within education 
institutions at basic levels, despite the creation and implementation of new methodological teaching proposals towards mastery of competences, in practice there have been disadvantages, such as numerous groups, which is a cause that hinders a good start-up of an adequate teaching-learning process.

An integral reform of education in Mexico [18] in each of the levels that integrate basic education, must be focused on providing students with a learning scheme based on the development and application of competencies. This learning scheme has been involved in a lag due to the educational models and teaching-learning media that are applied [19], where in general; the theory is reviewed and explained using media and materials such as printed texts and digital or virtual resources. Students understand little information and acquire knowledge that they do not know how to put it into practice beyond the classroom. In this way, these resources have been very badly exploited, leading to failure to inculcate the bases for the development of basic scientific training and the acquisition of notions about information technology and communications.

Trying to remedy the problem above mentioned and as a point in favor, it is well known that the new information and communication technologies have been little used, incredible as it may seem, being partially or totally outside the educational processes, since they reach to improve the educational didactics. In addition, these technologies facilitate the achievement of a broad and better integral development of the students, as much in their abilities of learning as of application of knowledge from basic levels of education.

In Mexico, the use of computing applications within the educational didactic is very little applied, or failing that, they are not correctly exploited in several of the school levels, specifically in primary education. When developing computing applications in the educational field, it is intended that their use provide an aid in teaching into the classroom, or being a useful tool to assist learning at home. This fact, leads to use the term, educational software, which is based on learning models, as well as concepts of cognitive and constructivist psychology. On the other hand, there is a subcategory known as virtual educational tutors, on which this paper is based.

The last integral reform of basic education in Mexico has as main challenge to raise the quality of education in the country, through continuous improvement of technological resources and high training of teachers and teaching to students, so that both take advantage of innovation present in the use of new didactic resources into the classroom. This may be possible through the incorporation of information and communication technologies into the professional training and pedagogical processes [20], taking for example the following ones:

- The use of digital tools and resources to support the understanding of knowledge and concepts.

- To plan and manage research, using information and communication technologies.

- $\quad$ To use models and simulations to explore some topics.

- To generate original products with the use of information and communication technologies, in which critical thinking, creativity, or the solution of problems based on real life situations are used.

- To make responsible use of software and hardware, whether working individually, in pairs or as a team. 
- To inculcate ethical, safe, and responsible use of Internet and digital tools as well.

Within the plans and programs of study of basic education in Mexico, the consolidation of a curriculum that encourages the development of competences in the use of information and communication technologies, is in response to the social demand and the quality of the Mexican public school [21]. To achieve this, it is known that the improvement of the infrastructure and equipment of the primary schools, in particular of their laboratories and workshops, is a priority. To do this, it must be based on digital technologies to equip students and teachers of devices and technological links.

It should be noted that in the first three grades of basic education, it is where the bases for the development of basic scientific training and the acquisition of notions about technology are established as mentioned in [22]. The context is clear, any educational reform should not evade digital skills standards, and through these it will be possible to teach the proper use of information and communication technologies, being the fundamental basis for the development and acquisition of skills [23].

\section{$4 \quad$ Virtual Tutor for Mexican Schoolchildren}

In an initial stage, there are some aspects to keep in mind while developing the virtual tutor into the Mexican education scene, which are the following ones:

- The benefited primary schools are some of those belonging to the municipalities of the State of Mexico in Mexico.

- The topics of the courses taken within the first three grades of primary education will be considered according to the current curriculum, which are: Spanish, Mathematics, Exploration of Nature and Society, Civic and Ethical Education, and finally, Artistic Education.

- Only some reinforcement exercises will be created, which will be taken as models to create the remaining ones in a final version of the virtual tutor.

- Students can choose the gender of the virtual tutor, as they feel better.

- The voice of the virtual tutor will be synthetic and will be reflected through a bidirectional dynamic dialogue, both to the student through text to speech and to the tutor through speech recognition.

- The virtual tutor will not be able to express emotions neither verbally nor visually. However, for a final future version this aspect will be fully covered.

\subsection{Module Description}

One of the most outstanding aspects in the design of the educational virtual tutor is the human-machine interaction, with an attractive design to capture the attention of the students, achieving an effective natural relationship in real time. The general outline of the prototype is shown in fig. 2, which is composed of three interconnected modules and multimedia components. The functionalities for each module are described as follows: 


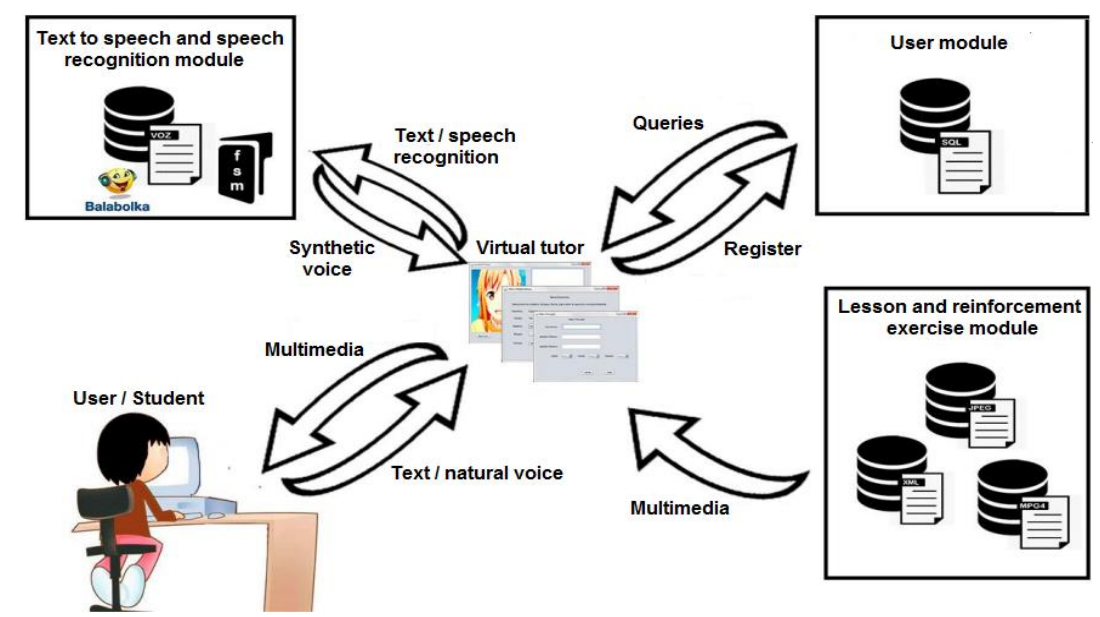

Fig. 2. General outline of the operation, design and implementation of the virtual tutor.

\subsubsection{User Module}

This module has a database where the basic data of the users will be registered, which are their names, paternal surname, maternal surname, age, grade, gender, password that will automatically generate the system, the school to which they belong, as well as the municipality where they are located. Thus, the virtual tutor will have information about each student to interact in a personalized and unique relationship.

\subsubsection{Lesson and Reinforcement Exercise Module}

This module is formed by a first database of images that are used in the reinforcement exercises and the possible personifications of the virtual tutor (female or male), with a caricature style; and a second database with explanatory videos on the topics that are addressed into the curriculum of the first three grades of primary education in Mexico; and finally, a third database with XML files based on the Java Speech API Markup Language, whose structure is in the form of a finite state machine, being considered for making decisions corresponding to the actions performed by students and the virtual tutor MeIPeAS.

\subsubsection{Text to Speech and Speech Recognition Module}

This module performs the action of converting the text introduced by the student through the keyboard or the options that he/she chooses to the personification of the virtual tutor's voice, that is, text-to-speech conversion. In addition, it is responsible for recognizing and processing the student's speech at the time the virtual tutor asks a question and waits for a verbal response. For the functioning of this module authorship code and open source solutions are used like the command line text to speech utilities voice.exe from Eli Fulkerson and speech.exe from Balabolka. However, MeIPeAS was created to also use commercial software such as Microsoft Speech Platform, CereProc and Amazon Speech Recognition Software. 


\subsection{Implementation as a Pedagogical Agent}

To personify the virtual tutor (see fig. 3), GIF images of caricatured appearance were used, as well as the corresponding animation to represent the speech action according to the case of the genre. The audio and speech animation in each GIF image are synchronized to denote a better naturalness during the interaction with the student.

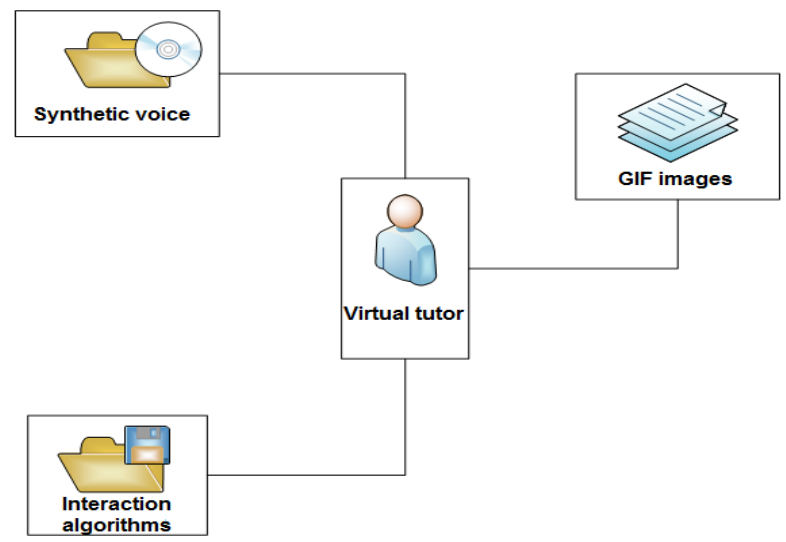

Fig. 3. Personification by means of synthetic voice and GIF image of the virtual tutor.

Once a student has started a session, he/she must choose in each subject the respective block and topic on which he/she wishes to obtain a review information and take the challenge of responding to a reinforcement exercise. This choice is made from the window shown in fig. 4. Fig. 5 shows the window used to start an exercise or well to exit to take another one from the window shown in fig. 4. The virtual tutor is representing by a female character.

As it is possible to notice, Spanish was used as the interface language given in the windows of the prototype as well as in the mechanism of interaction through the bidirectional dialogue with the virtual tutor. This is because in Mexico Spanish is the official language and the vast majority of schoolchildren who course the first three grades of primary education are having their first approaches with a second language such as English as a foreign language.

At the moment, only students can register and log in with the virtual tutor. However, it is intended that the teacher can do it equally but in such a way that he/she can have the options to add and modify lessons. A more ambitious challenge would be that this prototype could be available via the Internet, as well as be able to run on various platforms such as Android, IOS, Windows, and Linux systems.

Some primary schools from the municipalities of Atizapan de Zaragoza, Tlalnepantla de Baz and Nicolas Romero from the State of Mexico in Mexico were pilot testing scenarios. The prototype was presented to teachers and students from the first grade of basic education, as shown in fig. 6, doing the following:

- It was explained to the students and teachers about the prototype, the objectives that are sought to achieve, the benefits that this can have within the educational field and the way of interacting with the virtual tutor. 


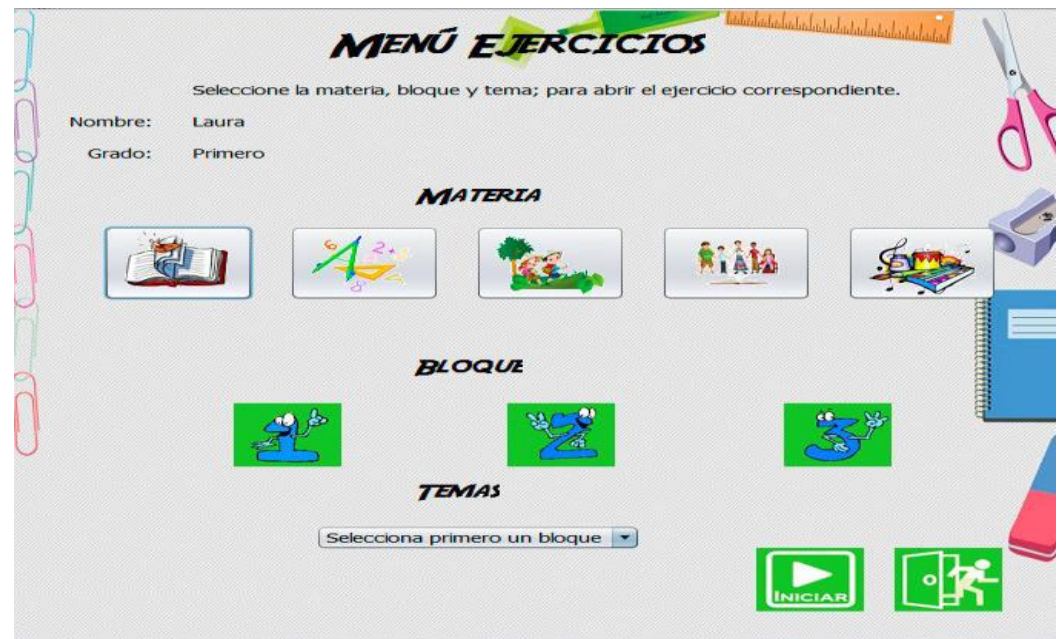

Fig. 4. Menu of exercises according for each subject.

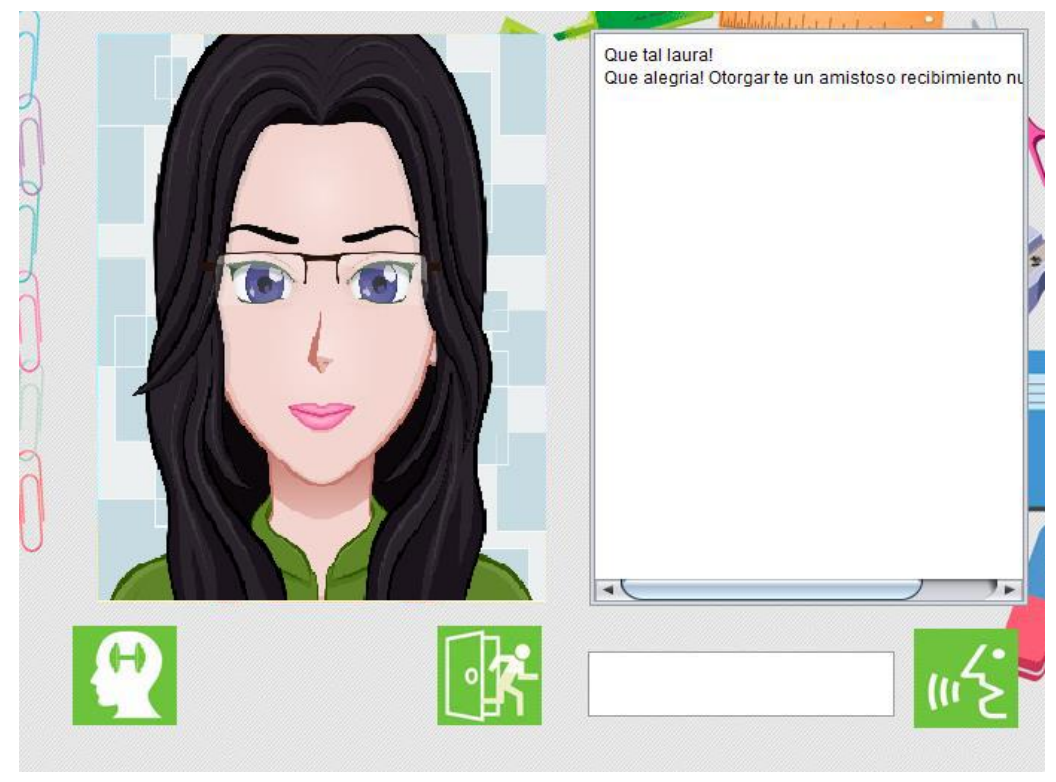

Fig. 5. Welcome to the student.

- A demonstration of the operation of the prototype was given, explaining from how it is executed, the content of each menu, the way they should register, how to $\log$ in and use the exercises, as well as the interaction with the virtual tutor.

- Once the explanation was completed, teams of students were formed to interact with the virtual tutor prototype. 


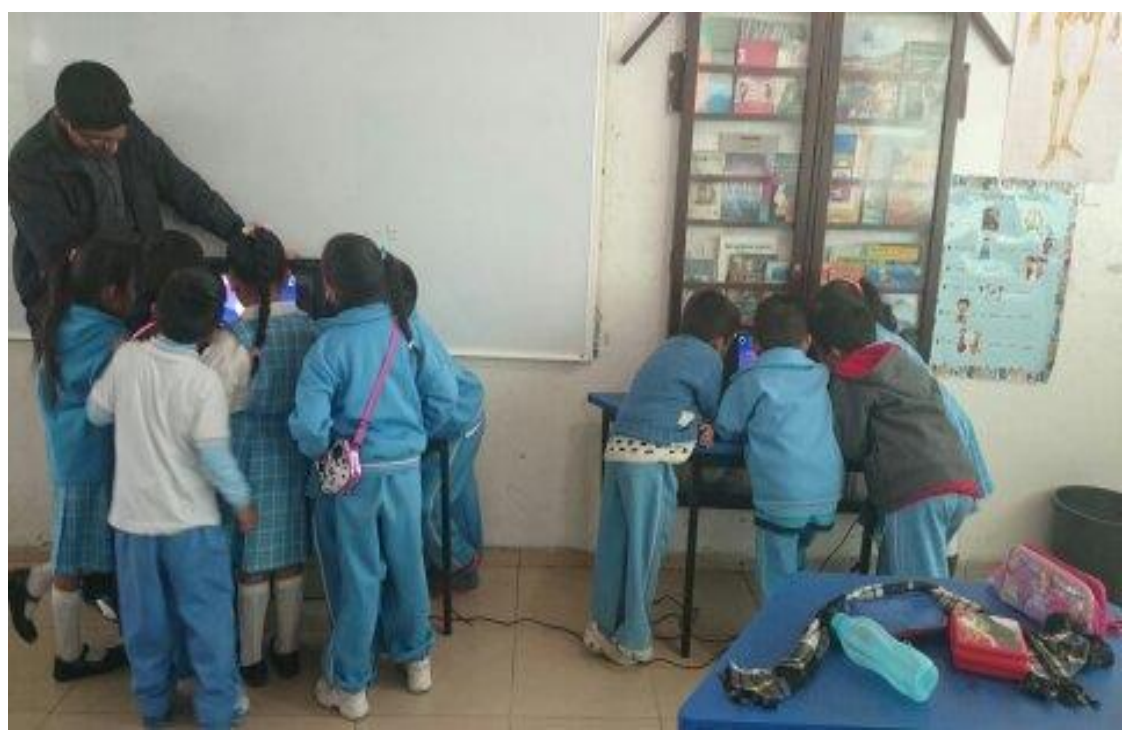

Fig. 6. Testing interaction scenario between students and the virtual tutor.

An example of reinforcement exercise performed is given in fig. 7. It is observed that the student must identify the animal shown by its name, in this case a gorilla. Other example of reinforcement exercise is shown in fig. 8, where a student has to identify the corresponding image to a body part asked by the virtual tutor. The virtual tutor is representing by a male character.

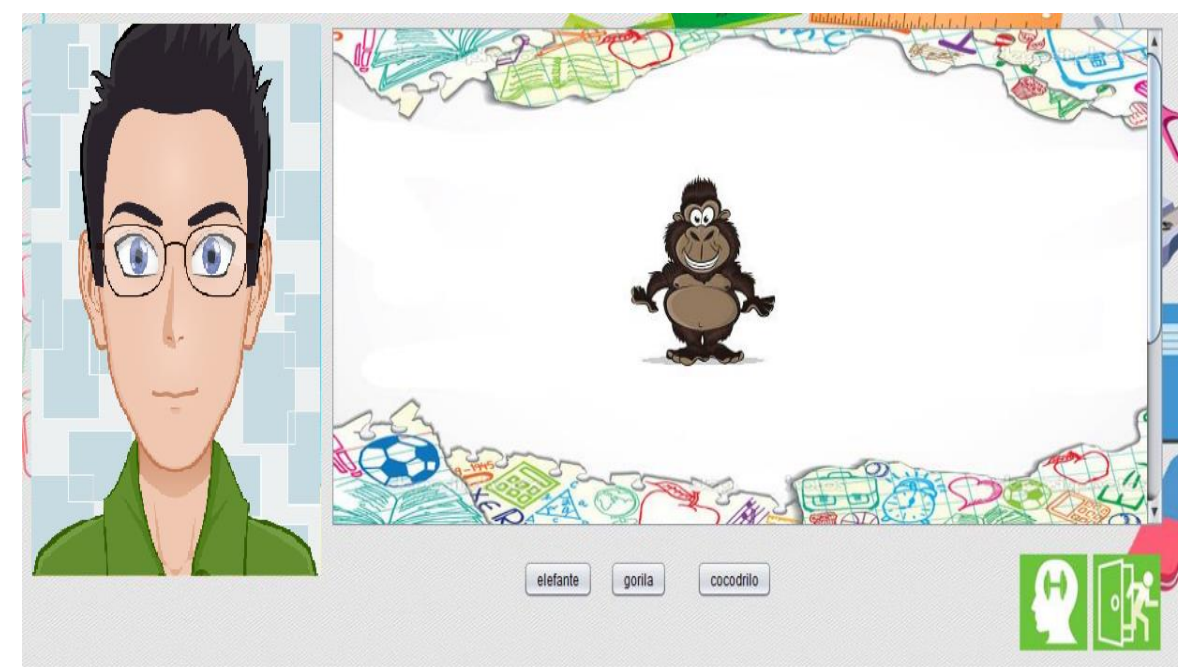

Fig. 7. Reinforcement exercise related to a Spanish course. 


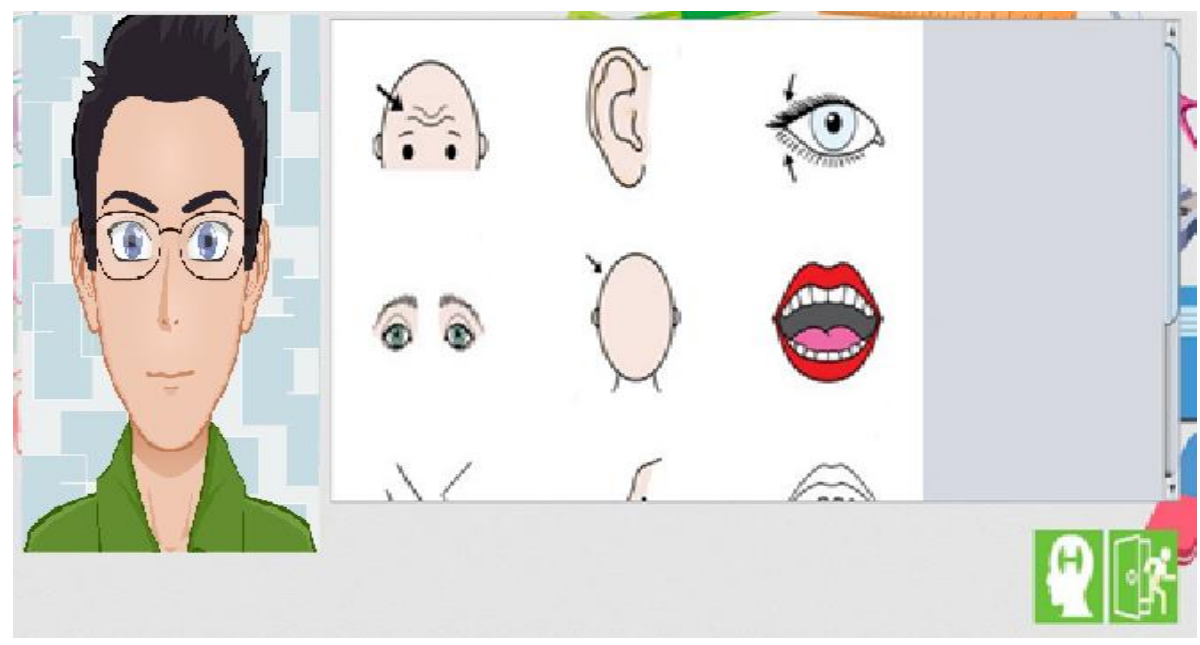

Fig. 8. Reinforcement exercise related to a Nature Exploration course.

At the end of the dynamics of interaction by students and teachers with the virtual tutor, was asked by 5 questions the appreciation of them with respect to the prototype to collect their user experience, the first 3 of yes/no type, the fourth with two possible answers, fun and boring, and for the last, the answer was left open. These questions were the following ones:

1. Do you know how to use a computer (basic level)?

2. Does your elementary school have a computer room?

3. Do you know what a virtual tutor is?

4. What did you think of the prototype of the virtual tutor?

5. How do you think a virtual tutor should be?

In total, 147 students, 7 were 5 years old (5\%), 125 were 6 years old (85\%) and 15 were seven years old (10\%) interacted with the virtual tutor, 72 boys (49\%) and 75 girls $(51 \%)$. Table 1 shows the percentages in the collected answers for the first four mentioned questions. Mainly, for the last question students coincided in their answers saying that a virtual tutor should be friendly, human-looking, colored and not scary. From the answers, it is verified that the user experience was positive and the proposed virtual tutor fulfills his task as a support tool within the teaching-learning process, being welcome and well appreciated by teachers and students.

Table 1. Answers and their percentages for questions to collect the user experience.

\begin{tabular}{|c|c|c|}
\hline Question & Answer 1 & Answer 2 \\
\hline 1 & Yes (40\%) & No (60\%) \\
\hline 2 & Yes (80\%) & No (20\%) \\
\hline 3 & Yes (25\%) & No (75\%) \\
\hline 4 & Funny (94\%) & \\
\hline
\end{tabular}




\section{$5 \quad$ Conclusions and Future Work}

Nowadays, there are many interesting and sophisticating research works about virtual tutors in support of children education, either in the teaching of a new language, as a help in learning for children with disorders such as autism, among others such as technologies for kindergarten children, and tools to teach them to read. Virtual environments for children education both in Mexico and in other countries have been created since the last three decades. However, it is always interesting the way in which such works are addressed, so the application areas can represent an innovation and contribution to the research field [24].

In this paper, a novel and interactive prototype of a virtual tutor was presented, which can be used as a support tool within the teaching-learning process in the first three grades of primary education in Mexico. For this, activities were created in which students come to reinforce the knowledge that is taught within the classroom. In this way, it is possible to bring information and communication technologies closer to children in the form of a human-computer interaction solution.

The presented virtual tutor has as main purpose to support the reinforcement of subjects taught in class, through reinforcement exercises, which allows generating a social and emotional interaction, managing to foster a natural and real-time relationship with students. To the authors' knowledge, MeIPeAS as a virtual tutor is unique and original in the pedagogical agent research field and one of the first created in Mexico for children education purposes.

It is worth mentioning that in its first prototype attempts, the virtual tutor here presented was made known in the 2014 Mexican Space of Science and Technology: The Era of Information and Communication Technologies, during the Workshop of Sociable Robots and Virtual Tutors on October 12, 2014. This event was held in the city of Toluca, State of Mexico in Mexico. From that day, the prototype was perfected and extended until achieving in 2018 what was described and presented here. This paper is one of the first related publications.

Proposing a prototype of an educational virtual tutor as a support tool that contributes and positively impacts educational didactics at the primary level in Mexico, opens the way to reflect and imagine new scenarios of information and communication technologies application [25] in conjunction with the exploitation of serious games and autonomous agents within the educational field [26] [27].

As work in the future, an extension of this prototype can be made to cover the other three missing grades of primary education in Mexico. In addition, other variants are possible to venture into other levels of education as at the university level, where the subjects of study are more complex, but are not exempt from being reinforced with the help of a virtual tutor.

As in similar works, a future extension for the prototype here exposed includes using the virtual tutor to provide support for self-explanation. This extension would be in terms of dialogues with students, where the agent makes questions to guide students in the teaching-learning process. Additionally, other extension is concerned with the use of a mixed short-term and long-term memory mechanism to create dialogues according to the progress of the students and what the virtual tutor remembers to provide customized feedback to them. 


\section{References}

1. Michael, D.R., Chen, S.L.: Serious games: Games that educate, train, and inform. Muska \& Lipman/Premier-Trade (2005)

2. Wouters, P., Van Nimwegen, C., Van Oostendorp, H., Van Der Spek, E.D.: A meta-analysis of the cognitive and motivational effects of serious games. Journal of educational psychology 105(2), 249-265 (2013)

3. Huang, R., Spector, J.M., Yang, J.: Learner Experiences with Educational Technology. Educational Technology. Springer, Singapore, pp. 91-105 (2019)

4. Passey, D., Dagiene, V., Atieno, L.V., Baumann, W.: Computational Practices, Educational Theories, and Learning Development. Problemos, pp. 24-38 (2019)

5. Johnson, W.L., Rickel, J.W., Lester, J.C.: Animated pedagogical agents: Face-to-face interaction in interactive learning environments. International Journal of Artificial Intelligence in Education 11(1), 47-78 (2000)

6. Morton, H., Jack, M.A.: Scenario-based spoken interaction with virtual agents. Computer Assisted Language Learning 18(3), 171-191 (2005)

7. Mitrovi, A., Suraweera, P.: Evaluating an animated pedagogical agent. In: International Conference on Intelligent Tutoring Systems, Springer, Berlin, Heidelberg, pp. 73-82 (2000)

8. Ashoori, M., Miao, C., Goh, E.S.: Toward a Model of Intelligence in Pedagogical agents (2009)

9. Ki, Y., Baylor, A.L.: Research-based design of pedagogical agent roles: A review, progress, and recommendations. International Journal of Artificial Intelligence in Education 26(1), 160-169 (2016)

10. Wise, B., Cole, R., Van Vuuren, S., Schwartz, S., Snyder, L.: Learning to read with a virtual tutor: Foundations to literacy. In: Ngampatipatpong and B. Pellom: Interactive literacy education: Facilitating literacy environments through technology, pp. 31-75 (2005)

11. Ward, W., Cole, R., Bolaños, D., Buchenroth-Martin, C., Svirsky, E., Vuuren, S.V., Becker, L.: My science tutor: A conversational multimedia virtual tutor for elementary school science. ACM Transactions on Speech and Language Processing (TSLP) 7(4), 1-29 (2011)

12. Atkinson, R.K., Mayer, R.E., Merrill, M.M: Fostering social agency in multimedia learning: Examining the impact of an animated agent's voice. Contemporary Educational Psychology 30(1), 117-139 (2005)

13. Blair, K., Schwartz, D.L., Biswas, G., Leelawong, K.: Pedagogical agents for learning by teaching: Teachable agents. Education Technology 47(1), 56-61 (2007)

14. Song, D.: Designing a Teachable Agent System for Mathematics Learning. Contemporary Educational Technology 8(2), 176-190 (2017)

15. Johnson, W.L., Lester, J.C.: Face-to-face interaction with pedagogical agents, twenty years later. International Journal of Artificial Intelligence in Education 26(1), 25-36 (2016)

16. Taub, M., Martin, S.A., Azevedo, R., Mudrick, N.V.: The role of pedagogical agents on learning: issues and trends. Handbook of Research on 3-D Virtual Environments and Hypermedia for Ubiquitous Learning, IGI Global, pp. 362-386 (2016)

17. Cuéllar, G.R.: La Reforma Integral de la Educación Básica en México (RIEB) en la educación primaria: desafíos para la formación docente. Revista electrónica interuniversitaria de formación del profesorado 15(1), 51-60 (2012)

18. Guichard, S.: The Education Challenge in Mexico: Delivering Good Quality Education to All. OECD Economics Department Working Papers, No. 447, OECD Publishing, Paris (2005)

19. Treviño Ronzón, E., Cruz Vadillo, R.: La Reforma Integral de la Educación Básica en el discurso docente: Análisis desde el ángulo de la significación. Perfiles educativos 36(144), 50-68 (2014)

20. Pelgrum, W.J.: Obstacles to the integration of ICT in education: results from a worldwide educational assessment. Computers \& Education 37(2), 163-178 (2001) 
21. Scott, D., Posner, C., Martin, C., Guzman, E.: The Education System in Mexico. UCL Press (2018)

22. Boudourides, M.: Constructivism, education, science, and technology. Canadian Journal of Learning and Technology/La revue canadienne de l'apprentissage et de la technologie 29(3), (2003)

23. Abbot, C.: ICT: Changing education. Routledge (2003)

24. Sottilare, R.A., Graesser, A., Hu, X., Holden, H. (Eds.): Design recommendations for intelligent tutoring systems, Volume 1-learner modeling. US Army Research Laboratory (2013)

25. Mellati, M., Khademi, M.: Technology-based education: Challenges of blended educational technology. Advanced online education and training technologies, IGI Global, pp. 4862 (2019)

26. Martha, A.S., Santoso, H.B.: The Design and Impact of the Pedagogical Agent: A Systematic Literature Review. Journal of Educators Online 16(1) (2019)

27. Payr, S.: The virtual university's faculty: An overview of educational agents. Applied Artificial Intelligence 17(1), 1-19 (2003) 